\title{
Cardiopulmonary function in fibrodysplasia ossificans progressiva
}

\author{
J M CONNOR, C C EVANS AND D A P EVANS
}

From the Department of Medicine, University of Liverpool, Liverpool

\begin{abstract}
Cardiopulmonary function was evaluated in 21 patients with fibrodysplasia ossificans progressiva. Neither cardiac enlargement nor failure was observed, but six patients had abnormal electrocardiograms. All had marked restrictive spirometry because of chest wall fixation and depended upon diaphragmatic respiration. The severity of chest restriction was independent of sex, age, duration of disease, and extent of other physical disability. Progression to chronic respiratory failure was not observed. Chest infection in the presence of diminished pulmonary reserve is the major hazard to life in this rare disease and prophylactic measures should be considered.
\end{abstract}

Fibrodysplasia ossificans progressiva (FOP, syn myositis ossificans progressiva) is a rare inherited disorder of connective tissue in which there is progressive ossification in voluntary muscles and ligaments in association with characteristic skeletal malformations. ${ }^{1}$ It was first reported in 1692 by Guy Patin $^{2}$ and 470 cases had been reported from all ethnic groups by $1976 .{ }^{3}$ There have been several excellent reviews of the voluminous literature of this subject ${ }^{1-6}$ but, because of its rarity, most authors have studied only one or two patients with the disease. It is inherited as an autosomal dominant disorder. However, patients rarely reproduce because of physical handicap and thus virtually all cases are fresh mutations with a negative family history. ${ }^{1} 78$ The mechanism by which this abnormal gene produces its effects is unknown and therapy has been largely empirical and not of proven value. ${ }^{6}$

Characteristic digital anomalies are present in virtually all patients with FOP. ${ }^{69}$ Most commonly the big toes are shortened with or without valgus deviation and radiographs reveal deformity of the first metatarsals and a single phalanx in each big toe (figs 1,2). Changes in the hands are less frequent and include short first metacarpals and incurving of the fifth digits (fig 3). These anomalies are present at birth and provide important, though often overlooked, diagnostic clues. ${ }^{6}$ Extraskeletal bone formation usually presents as a series of localised swellings

Address for reprint requests: Dr JM Connor, Department of Medicine, University of Liverpool, PO Box 147, Liverpool L69 3BX. in the muscles of the neck or back (fig 4). This is usually evident by 10 years, but may occasionally be delayed until adult life. ${ }^{5}$ Axial musculature bears the brunt of the disease and limb involvement tends to be restricted to their proximal parts. ${ }^{5}$ The disease progresses erratically with periods of apparent inactivity of up to several years but severe physical disability is the rule: the end result being a literal "stone man".

The diaphragm never ossifies in FOP but ankylosis of the costovertebral joints with chest wall fixation is the major prognostic factor. ${ }^{16}$ Patients usually die in their third or fourth decades. ${ }^{10}$ The usual cause of death in recorded cases has been pneumonia, ${ }^{1311}$ but some authors ${ }^{712}$ believe that chronic respiratory failure may occur. Pulmonary function tests, however, have been recorded in only eight patients with FOP. ${ }^{313-18}$ These authors found restrictive ventilatory defects and reduced lung volumes. Arterial blood gases have been measured in three FOP patients ${ }^{13} 1417$ and were normal. The heart is said to be normal, ${ }^{1}$ although there are three reports of abnormal electrocardiograms in patients with FOP. ${ }^{5} 1920$ The abnormalities found were right bundle branch block, ${ }^{5}$ left axis deviation with ST segment changes, ${ }^{20}$ and supraventricular tachycardia. ${ }^{19}$ Few detailed postmortem studies have been published $^{13}$ and these have concentrated on the changes in the muscles.

In view of the paucity of studies in this area we wish to report upon the cardiopulmonary status in a large series of patients with FOP. 


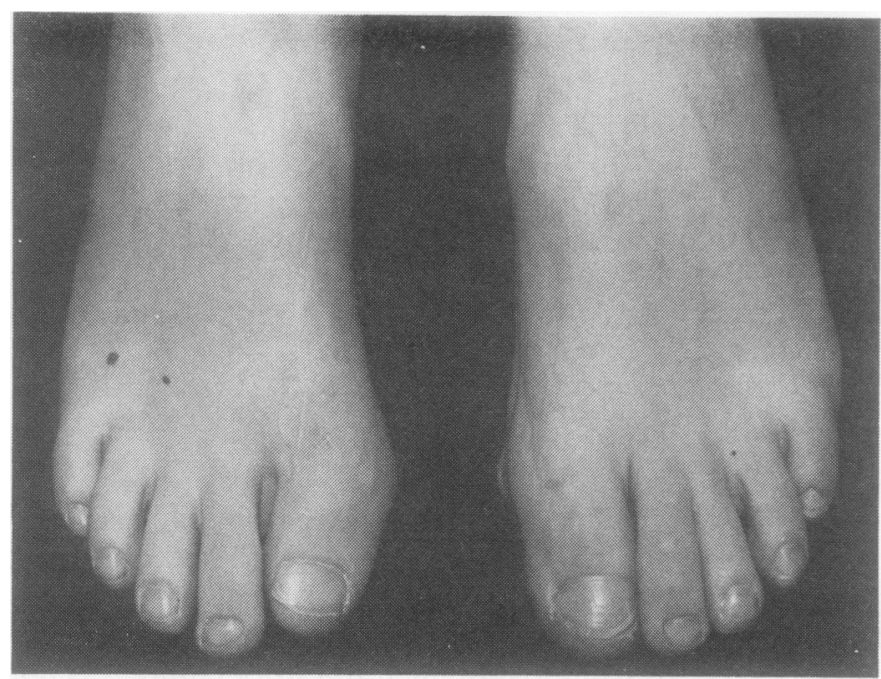

Fig 1 Typical big toe deformity in fibrodysplasia ossificans progressiva.

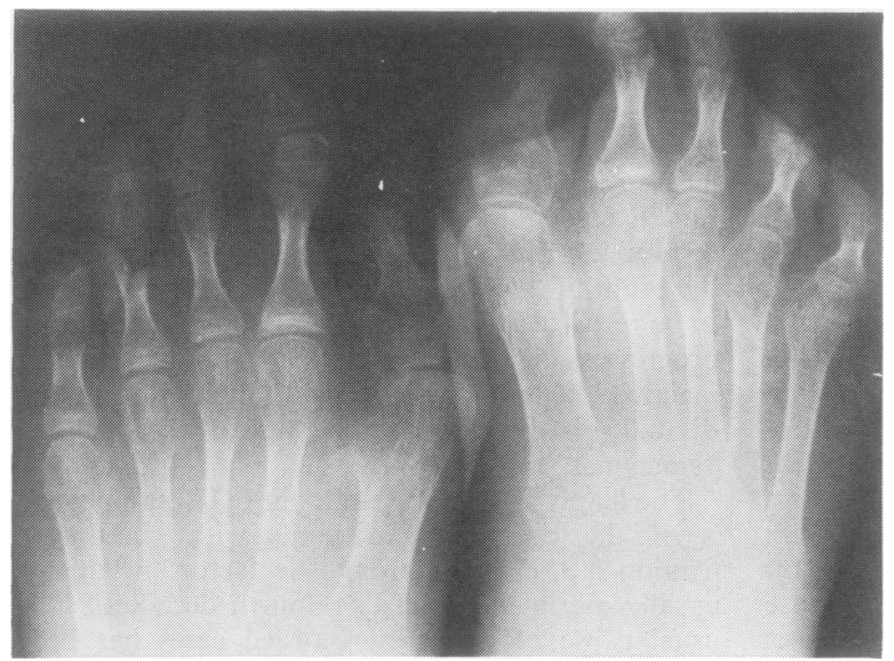

Fig 2 Monophalangic big toes and deformed first metatarsals in fibrodysplasia ossificans progressira.

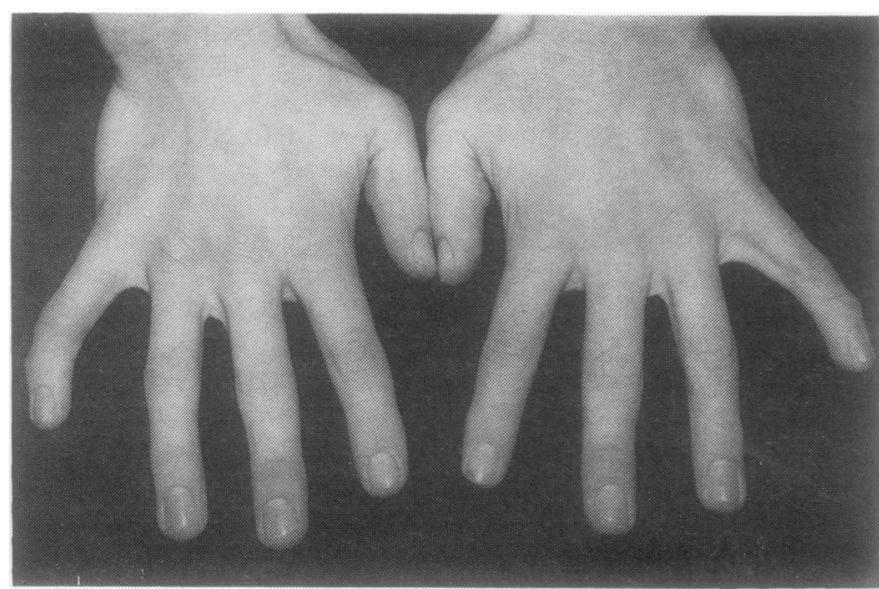

Fig 3 Short first metacarpals and incurving of little fingers in fibrody'splasia ossificans progressiva. 


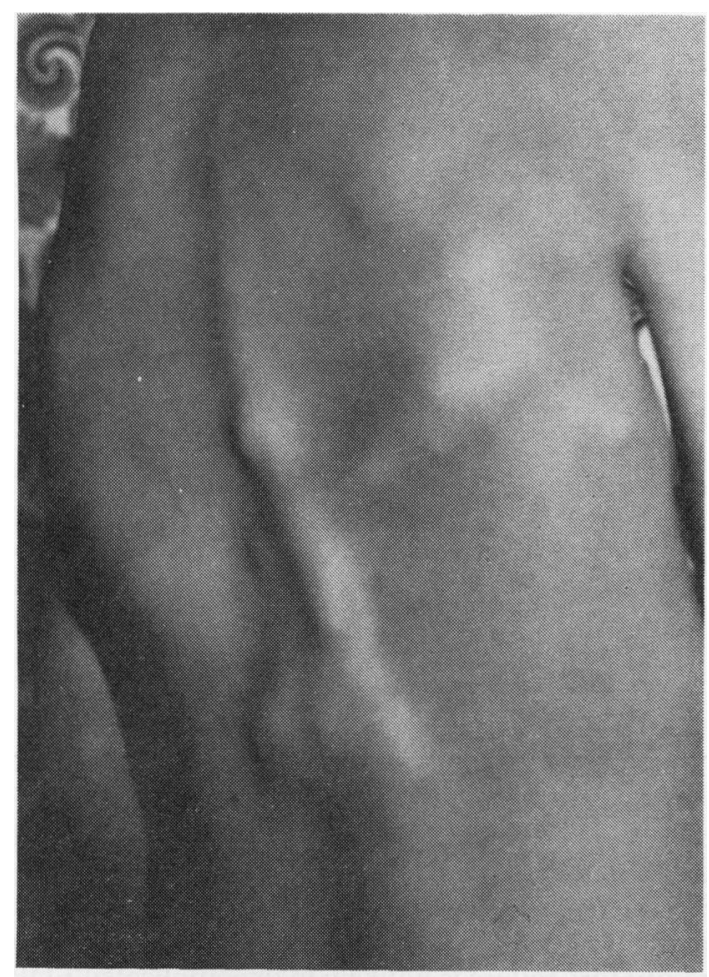

Fig 4 Paraspinal ossification in a 14-year-old patient with fibrodysplasia ossificans progressiva.

\section{Methods}

Patients with FOP were discovered by means of a national questionnaire and a survey of disabled associations. In all cases the diagnosis was confirmed by personal evaluation and in view of the patients' disability home assessments were made. The assessment consisted of a history, physical examination, electrocardiogram, peak expiratory flow measurement with a Wright Peak Flow Meter, and spirometry using a Vitalograph spirometer. Predicted values were according to Cotes. ${ }^{21}$ Pulmonary function tests were performed with the patients in a standing position except for seven patients (numbers 3, 4, $5,12,15,18,20$-table) who are confined to wheelchairs and appropriate corrections were made for their predicted values. ${ }^{21}$ In three longstanding cases (numbers 1, 15, 18) arterial blood gases were taken. Where possible the patients' clinical records and radiographs were reviewed.

\section{Results}

Cardiopulmonary function was assessed in 21 patients with FOP. There were 10 males and 11 females. They had an age range of 6-70 years with a mean of $30 \cdot 2$ years. All patients had digital anomalies in addition to ectopic ossification. Ectopic ossification was evident in all patients by 10 years and had a mean age of onset of $3 \cdot 3( \pm 2 \cdot 43)$ years. The paraspinal musculature was the initial site of involvement in 16 patients and all had severe limitation of spinal movements by 15 years of age. The mean age of severe spinal limitation was $5 \cdot 7$ years $(S D \pm 3 \cdot 61)$. Only two of these patients (numbers 3 and 11) had a moderate scoliosis. In both of these it was situated in the mid-thoracic region and was concave to the left. The extent of other physical handicap was more variable and will be described elsewhere in detail.

No patient had any cardiorespiratory symptoms and none had ever smoked cigarettes. Results of pulmonary function tests are presented in the table. Chest expansion was reduced in all patients and had a range of $0-3 \mathrm{~cm}$ and a mean of $1.4 \mathrm{~cm}$. FEV when expressed as a percentage of its predicted value was reduced in all patients and had a range of $27-64 \%$ and a mean of $45 \%(S D \pm 13 \cdot 0)$. FVC when expressed as a percentage of its predicted value was also reduced in all patients and had a range of 23-63 and a mean of $40 \%(\mathrm{SD} \pm 13 \cdot 2)$. The $\mathrm{FEV}_{1} /$ FVC percentage was in excess of $80 \%$ in all patients. Only one patient achieved his predicted peak expiratory flow rate. The degree of lung restriction in these patients was independent of sex, age, duration of disease, or extent of other physical handicap. No patient was centrally cyanosed and arterial blood gases were normal in three patients with longstanding chest wall fixation (numbers $1,15,18$ ).

No patient had cardiac enlargement or failure detectable on physical examination. Six patients however, had abnormal electrocardiograms: patients 1,2 , and 18 had $\mathrm{T}$ wave inversion in the inferior leads, and patients 3,5 , and 17 had right bundle branch block. Chest radiographs were available for study on 12 of the patients. These all showed ectopic ossification in the voluntary muscles of the chest wall, but no evidence of cardiac, diaphragmatic, or pulmonary ossification (fig 5). No patient had clinical or radiological evidence of upper lobe fibrosis.

\section{Discussion}

Abnormal pulmonary function is an early and consistent feature of FOP. A restrictive ventilatory defect caused by chest wall fixation is typical and does not appear to progress during adult life. This reflects the characteristic predilection for involvement of the axial muscles and joints. ${ }^{5}$ All our patients had severe limitation of spinal movements and chest wall expansion by 15 years of age and in many such limitation was evident many years earlier. Thus 
Table Pulmonary function tests in 21 patients with FOP. FEV $V_{1}$ and FVC are given in actual values and as percentages of their predicted values, ${ }^{21}$ corrected for age, sex, height, and posture. The peak expiratory flow rate predicted values ${ }^{21}$ are given in parentheses

\begin{tabular}{|c|c|c|c|c|c|c|c|c|}
\hline Number & $\operatorname{Sex}$ & Height $(\mathrm{cm})$ & Age $(y r)$ & $\begin{array}{l}\text { Chest } \\
\text { expansion } \\
(\mathrm{cm})\end{array}$ & $F E V_{1}(l)$ & $F V C(I)$ & $\begin{array}{l}F E V \mid F V C \\
(I \%)\end{array}$ & Peak flow (l!min) \\
\hline 1 & $\mathbf{F}$ & 163 & 25 & 2 & $0.95(30 \%)$ & $1.0 \quad(27 \%)$ & 95 & $175(440)$ \\
\hline 2 & $\mathbf{F}$ & 153 & 27 & $1 \cdot 5$ & $0.85(30 \%)$ & $0.85(27 \%)$ & 100 & $175(400)$ \\
\hline 3 & $\mathbf{F}$ & 173 & 60 & 0 & $0.65(27 \%)$ & $0.8 \quad(23 \%)$ & 81 & $145(410)$ \\
\hline 4 & $\mathrm{~F}$ & 173 & 57 & $2 \cdot 2$ & $0.85(33 \%)$ & $1.0(28 \%)$ & 85 & $210(410)$ \\
\hline 5 & $\mathbf{M}$ & 175 & 30 & 2 & $2 \cdot 1 \quad(52 \%)$ & $2 \cdot 25(46 \%)$ & 93 & $350(620)$ \\
\hline 6 & $\mathbf{M}$ & 155 & 14 & $1 \cdot 8$ & $1.55(47 \%)$ & $1.6(41 \%)$ & 97 & $260(380)$ \\
\hline 7 & $\mathbf{M}$ & - & 6 & 0.5 & - & - & - & $60(110)$ \\
\hline 8 & $\mathbf{M}$ & 160 & 19 & 2 & $2 \cdot 2 \quad(61 \%)$ & $2.3(55 \%)$ & 96 & $400(575)$ \\
\hline 9 & $\mathbf{M}$ & 152 & 16 & $1 \cdot 5$ & $1.6(61 \%)$ & $1.7(55 \%)$ & 94 & $360(360)$ \\
\hline 10 & $\mathbf{F}$ & 162 & 28 & 0.5 & $1 \cdot 2(40 \%)$ & $1 \cdot 2(33 \%)$ & 100 & $130(430)$ \\
\hline 11 & $\mathbf{F}$ & 183 & 32 & $2 \cdot 5$ & $1 \cdot 1 \quad(31 \%)$ & $1.2(26 \%)$ & 92 & $280(490)$ \\
\hline 12 & $\mathbf{F}$ & 165 & 30 & $1 \cdot 5$ & $0.95(31 \%)$ & $1.05(28 \%)$ & 90 & $220(440)$ \\
\hline 13 & $\mathbf{M}$ & 170 & 39 & 0 & $2.25(63 \%)$ & $2.65(60 \%)$ & 85 & $400(570)$ \\
\hline 14 & $\mathbf{M}$ & 178 & 27 & 2 & $1.95(46 \%)$ & $1.95(38 \%)$ & 100 & $230(630)$ \\
\hline 15 & $\mathbf{F}$ & 160 & 32 & 1 & $1.8(53 \%)$ & $1.8 \quad(45 \%)$ & 100 & 385 (420) \\
\hline 16 & $\mathbf{M}$ & 178 & 19 & 0 & $1.25(29 \%)$ & $1.4(27 \%)$ & 89 & $175(640)$ \\
\hline 17 & $\mathbf{M}$ & 163 & 30 & 3 & $1.65(46 \%)$ & $1.65(39 \%)$ & 100 & $275(570)$ \\
\hline 18 & $\mathbf{F}$ & 160 & 70 & 0 & - & - & - & $95(340)$ \\
\hline 19 & $\mathbf{M}$ & 157 & 15 & 3 & $1.85(64 \%)$ & $2.0 \quad(59 \%)$ & 93 & $310(390)$ \\
\hline 20 & $\mathbf{F}$ & 157 & 35 & $1 \cdot 5$ & $1.3(48 \%)$ & $1.3(39 \%)$ & 100 & $265(400)$ \\
\hline 21 & $\mathbf{F}$ & 142 & 24 & 0 & $1.45(57 \%)$ & $1.65(63 \%)$ & 88 & $310(360)$ \\
\hline
\end{tabular}

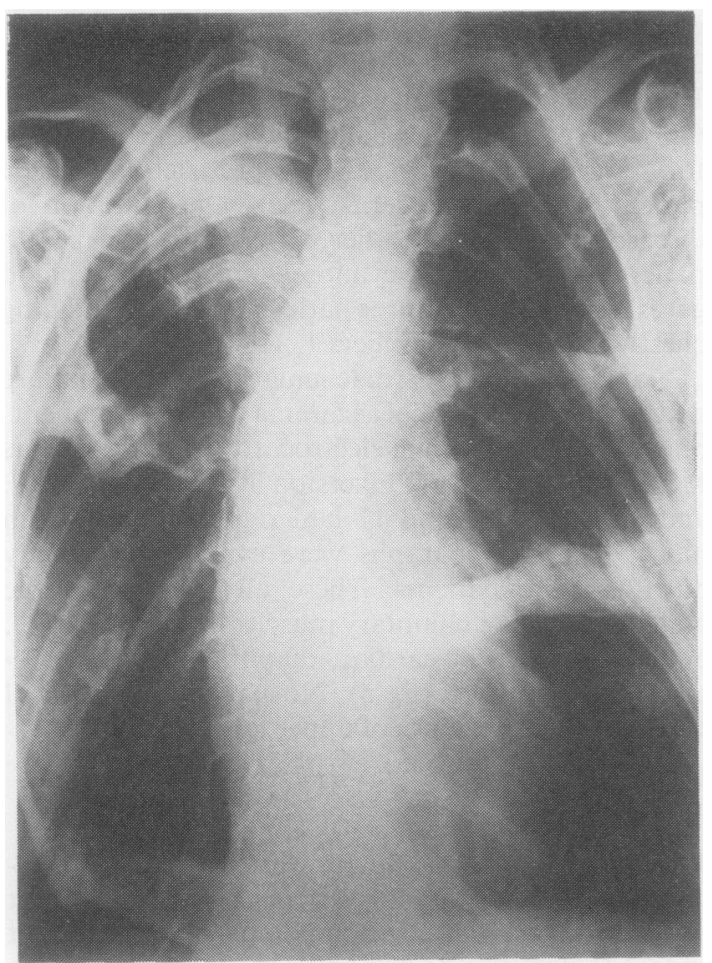

Fig 5 Chest radiograph showing extraskeletal ossification in fibrodysplasia ossificans progressiva.

adults with FOP have usually reached their maximum disability with regard to spinal and chest wall restriction and pulmonary function at this stage is maintained by the uninvolved diaphragm. Such diaphragmatic function is adequate for the basal requirements of these patients with restricted mobility and we believe that progression to chronic respiratory failure is unlikely in uncomplicated FOP. This belief is supported by the normal arterial blood gases in three patients in our study and in three patients in the literature. ${ }^{13} 1417$

Our FOP patients had a high prevalence $(29 \%)$ of abnormal electrocardiograms. Right bundle branch block may be occasionally found in otherwise normal individuals ${ }^{22}$ and might be coincidental, but the $T$ wave changes in the inferior leads cannot be thus explained. Cardiac ossification has never been recorded in FOP $^{1}$ and was not evident on the radiographs of our patients. Chronic respiratory failure was not observed so cor pulmonale is untenable. It is therefore speculative if these abnormal electrocardiograms reflect involvement of the cardiac connective tissue by the disease process in FOP and further detailed pathological examinations should help to resolve this point.

FOP has some similarities to ankylosing spondylitis. Both result in spinal rigidity and restrictive pulmonary function due to ankylosis of costo- $\stackrel{\infty}{\rightarrow}$ vertebral joints. ${ }^{23}$ In ankylosing spondylitis the limitation of chest wall expansion is well compensated by diaphragmatic movement until the thorax is severely affected. ${ }^{24}$ Chronic respiratory failure and cor pulmonale do not occur in uncomplicated ankylosing spondylitis. ${ }^{23}$ Upper lobe fibrosis is an occasional complication of ankylosing spondylitis with 16 reported cases by $1971^{25}$ This is probably 
a component of the primary disease process ${ }^{26}$ but it has been proposed that it might be secondary to pulmonary hypoventilation. ${ }^{27}$ The former theory is supported by our lack of observation of this upper lobe fibrosis in FOP patients who generally have a more severe restrictive defect than patients with ankylosing spondylitis.

Severe upper thoracic kyphoscoliosis is a recognised cause of chronic respiratory failure and cor pulmonale. ${ }^{23}$ None of our patients had such a severe high deformity and care should be taken to avoid spinal fixation in such a position in FOP. Otherwise irreversible progression to chronic repiratory failure is unlikely in FOP, and attention should be directed towards the prevention and therapy of intercurrent chest infections. Such measures might include: chest physiotherapy, prompt antibiotic treatment of early chest infection, pneumococcal and influenzal vaccines. Obviously factors which will interfere with diaphragmatic respiration, such as upper abdominal surgery, should be avoided if possible. Such measures will undoubtedly prolong life for patients with FOP while research is directed towards understanding and halting the basic disease process.

We are indebted to the consultants throughout Britain who have allowed us to study their patients with FOP.

\section{References}

1 McKusick VA. Heritable disorders of connective tissue. Fourth edition. St Louis: CV Mosby, 1972; 687-702.

2 Patin G. Lettres choisies de feu Monsieur Guy Patin. Letter of 27 August 1648 written to AF. Cologne: Laurens, 1692; 1 :28.

3 Suzuki T, Ishikawa S, Akanuma N, Tsunoda $\mathrm{H}$. Myositis ossificans progressiva with parathyroid hyperplasia and polycystic ovary. Acta Path Jap 1976; 26:251-62.

4 Rosenstirn J. A contribution to the study of myositis ossificans progressiva. Ann Surg 1918; 68:485-520, 591-637.

5 Lutwak L. Myositis ossificans progressiva. Mineral, metabolic and radioactive calcium studies of the effects of hormones. Am J Med 1964; 37:269-93.

6 Smith R. Myositis ossificans progressiva: a review of current problems. Semin Arthritis Rheum 1975; 4:369-80.

7 Tunte W, Becker PE, Knorre Gv. Zur genetik der myositis ossificans progressiva. Humangenetic 1967; 4:320-51.
8 Connor JM, Evans DAP. The genetics of fibrodysplasia ossificans progressiva. J Med Genet 1981; in press.

9 Schroeder HW, Zasloff M. The hand and foot malformations in fibrodysplasia ossificans progressiva. Johns Hopkins Med J 1980; 147:73-8.

10 Vastine $\mathrm{JH}$, Vastine MF, Arango O. Myositis ossificans progressiva in homozygotic twins. $A J R$ 1948;59:204-12.

11 Russell RGG, Smith R, Bishop MC, Price DA, Squire CM. Treatment of myositis ossificans progressiva with a diphosphonate. Lancet 1972; 1:10-11.

12 Azmy A, Bensted JPM, Eckstein HB. Myositis ossificans progressiva. $Z$ Kinderchirurg 1979; 26: 252-8.

13 Schonthal H. Atemmechanische probleme bei der myositis ossificans progressiva. Beitr Klin Erforsch Tuberk 1967; 135:322-4.

14 Letts RM. Myositis ossificans progressiva. A report of two cases with chromosome studies. Canad Med Assoc J 1968; 99:856-62.

15 Weiss IW, Fisher L, Phang JM. Diphosphonate therapy in a patient with myositis ossificans progressiva. Ann Intern Med 1971; 74:933-6.

16 Bland JH, Kirschbaum B, O'Connor GT, Whorton E. Myositis ossificans progressiva. Effect of intravenously given parathyroid extract on urinary excretion of connective tissue components. Arch Intern Med 1973; 132:209-12.

17 Buhain WJ, Rammohan G, Berger HW. Pulmonary function in myositis ossificans progressiva. $\mathrm{Am} \mathrm{Rev}$ Respir Dis 1974; 110:333-7.

18 Hentzer B, Jacobsen HH, Asboe-Hansen G. Fibrodysplasia ossificans progressiva. Scand $J$ Rheum 1977; 6:161-71.

19 Campbell RK. Myositis ossificans progressive. Radiol Rev 1933; 55:153-6.

20 Fletcher E, Moss MS. Myositis ossificans progressiva. Ann Rheum Dis 1965; 24:267-72.

21 Cotes JE. Lung function-assessment and application in medicine. Third edition. Oxford: B ackwell Scientific Publications, 1975.

22 Shaffer AB, Reiser I. Right bundle branch system block in healthy young people. Am Heart $J 1961$; 62:487-93.

23 Bates DV, Macklem PT, Christie RV. Rest iratory function in disease. Second edition. Philadelphia: WB Saunders, 1971.

24 Zorab PA. The lungs in ankylosing spondylitis. QJ Med 1962; 31:267-80.

25 Leading article. The lungs in ankylosing spondylitis. Br Med J 1971; 3:492-3.

26 Campbell AH, MacDonald CB. Upper lobe fibrosis associated with ankylosing spondylitis. $\mathrm{Br} J \mathrm{Dis}$ Chest 1965; 59:90-101.

27 Jessamine AG. Upper lung lobe fibrosis in ankylosing spondylitis. Canad Med Ass J 1968; 98:25-9. 